THE influence of circulating serotonin (5-HT) on the effects of intra-articular administration of granisetron on temporomandibular joint (TMJ) pain was investigated in 11 patients with chronic polyarthritides. An analgesic effect superior to placebo has been shown previously.

The change in TMJ movement pain intensity was negatively correlated to circulating $5-\mathrm{HT}$; that is, the higher the 5-HT before injection, the greater the reduction of pain intensity. The resting pain intensity reduction was not related to 5-HT.

In conclusion, this study indicates a stronger shortterm analgesic effect on TMJ movement pain by intraarticular administration of the $5-\mathrm{HT}_{3}$ receptor antagonist granisetron in patients with high levels of circulating 5-HT.

Key words: $5-\mathrm{HT}_{3}$ receptor, Arthritis, Blood, Nociception, Pain, Rheumatoid arthritis, Serotonin, Serum, Temporomandibular joint

\section{Influence of serotonin on the analgesic effect of granisetron on temporomandibular joint arthritis}

\author{
Ülle Voog ${ }^{1,2}$, Per Alstergren ${ }^{1, C A}$, Edvitar Leibur2, \\ Riina Kallikorm ${ }^{3}$ and Sigvard Kopp ${ }^{1}$
}

${ }^{1}$ Department of Clinical Oral Physiology, Institute of Odontology, Karolinska Institutet, Box 4064, 14104 Huddinge, Sweden; ${ }^{2}$ Department of Stomatology and ${ }^{3}$ Department of Internal Medicine, Faculty of Medicine, University of Tartu, 8 L Puusepa Str, 2400 Tartu, Estonia

\author{
${ }^{\mathrm{CA}}$ Corresponding Author \\ Tel: +46852488170 \\ Fax: +4686080881 \\ E-mail: per.alstergren@ofa.ki.se
}

\section{Introduction}

Temporomandibular joint (TMJ) pain is a significant part of the symptomatology and impairment of daily life in patients with TMJ involvement of chronic polyarthritides such as rheumatoid arthritis (RA). ${ }^{1}$ The monoamine serotonin $(5-\mathrm{HT})$ mediates pain and hyperalgesia, ${ }^{2}$ and has been found to be associated with TMJ pain upon joint movement and associated impairment of mobility. ${ }^{3}$ Peripheral 5-HT is mainly stored in thrombocytes, and several signal substances involved in the mediation of inflammation can induce 5-HT release from these cells. ${ }^{4,5}$ In patients with RA, thrombocytes have been found to be increased in number and to release 5 -HT. ${ }^{4}$ Richardson and Engel showed that 5-HT participates in the mediation of resting pain from inflamed peripheral tissues by sensitizing or exciting fine afferent units via the 5- $\mathrm{HT}_{3}$ receptor. ${ }^{6}$ This receptor is peripherally located only on afferent neurons. ${ }^{7}$ In a recent study of patients with RA, intra-articular injection of $1 \mathrm{mg}$ of the $5-\mathrm{HT}_{3}$ receptor antagonist granisetron was found to reduce TMJ resting pain for at least $20 \mathrm{~min}$ and injection of granisetron into the healthy human masseter muscle reduced pain induced by local administration of $5-\mathrm{HT}{ }^{8,9}$ It therefore seems probable that the $5-\mathrm{HT}_{3}$ receptor is involved in the modulation of musculoskeletal pain. The analgesic effect of granisetron most probably depends on the cell-surface expression of $5-\mathrm{HT}_{3}$ receptors on the local nerve endings and on the local tissue level of 5-HT. However, the influence of circulating 5-HT, which is the major source of tissue 5-HT, on the response to granisetron is unknown. The aim of this study was therefore to investigate the influence of circulating 5-HT on the effects on TMJ pain by intra-articular administration of granisetron in patients with chronic polyarthritides.

\section{Materials and methods}

\section{Patients}

Eleven patients (10 females and one male) with a median (interquartile range) age of 40 (22) years with signs (localized pain) of TMJ involvement by chronic polyarthritides were included (Table 1). The diagnosis of RA (three patients) was determined according to the 1987 classification criteria of the American College of Rheumatology, ${ }^{10}$ while the diagnosis of psoriatic arthritis (one patient), ankylosing spondylitis (one patient), reactive polyarthritis (two patients), Sjögren's syndrome (one patient) or chronic unspecific polyarthritis (three patients) was determined according to the European Spondylarthropathy Study Group's criteria. ${ }^{11}$

The patients were first referred to the Department of Rheumatology at the University of Tartu, Estonia from general practitioners or rheumatologists in Estonia. After an inclusion examination at the rheu- 
Table 1. Demographic and background factors in 11 patients with chronic polyarthritides receiving injections of $3 \mathrm{mg} / 3 \mathrm{ml}$ of granisetron into the temporomandibular joint (TMJ)

\begin{tabular}{|c|c|c|}
\hline Parameter & Median & $\begin{array}{l}\text { Interquartile } \\
\text { range }\end{array}$ \\
\hline Age (years) & 40 & 22 \\
\hline \multicolumn{3}{|l|}{ Duration $^{\mathrm{a}}$} \\
\hline General disease (years) & 5 & 7 \\
\hline TMJ disease (years) & 1 & 2 \\
\hline \multicolumn{3}{|l|}{ Pre-injection TMJ pain intensity } \\
\hline \multicolumn{3}{|l|}{ Rest } \\
\hline Injected side (VAS) & 21 & 22 \\
\hline Contralateral side (VAS) & 0 & 1 \\
\hline \multicolumn{3}{|l|}{ Maximum mouth opening } \\
\hline Injected side (VAS) & 39 & 22 \\
\hline Contralateral side (VAS) & 0 & 2 \\
\hline \multicolumn{3}{|l|}{ Background factors } \\
\hline $\begin{array}{l}\text { Number of symptomatic joint } \\
\text { regions }\end{array}$ & 3 & 2 \\
\hline $\begin{array}{l}\text { Erythrocyte sedimentation rate } \\
(\mathrm{mm} / \mathrm{h})\end{array}$ & 16 & 26 \\
\hline C-reactive protein (mg/l) & 5 & 12 \\
\hline $\begin{array}{l}\text { Thrombocyte particle count } \\
\left(10^{9} / l\right)\end{array}$ & 265 & 102 \\
\hline Rheumatoid factor (IU/ml) & 0 & 0 \\
\hline \multicolumn{3}{|l|}{ Serotonin } \\
\hline Serum (nmol/l) & 668 & 531 \\
\hline Plasma (nmol/l) & 10 & 9 \\
\hline
\end{tabular}

VAS, visual analogue scale.

matology clinic, the patients were referred to the Department of Stomatology at the same university. Inclusion criteria were diagnosis of chronic polyarthritis, resting pain localized to the TMJ region and a reduction in TMJ pain intensity upon maximum mouth opening of $35 \%$ or more after an auriculotemporal nerve block with $2 \mathrm{ml}$ of $2 \%$ lidocaine $(20 \mathrm{mg} / \mathrm{ml}$ of Xylocain; Astra-Zeneca, Södertälje, Sweden). Exclusion criteria were pregnancy and allergic reactions to granisetron or any other disease that may cause pain in the TMJ region. All patients used non-steroid anti-inflammatory drugs, three patients used oral glucocorticoids and three patients used disease-modifying antirheumatic drugs. The patients had not been subjected to any recent ( $<3$ months) treatment of the TMJ. The study was approved by the local ethics committees at the University of Tartu, Estonia (94/3, 01) and the Huddinge University Hospital, Sweden (151/01). All individuals gave their verbal consent.

\section{Procedures}

After the inclusion examination, the current resting pain intensity and the pain intensity during maximum mouth opening of the TMJ were assessed with a 100 $\mathrm{mm}$ visual analogue scale (ACO, Stockholm, Sweden) with end-points marked 'No pain' and 'Worst pain ever experienced'. The pain intensities were assessed before the injection as well as at every fifth minute during the first $30 \mathrm{~min}$ and then every 10th min up to $60 \mathrm{~min}$. Three $\mathrm{ml}$ of the $5-\mathrm{HT}_{3}$ antagonist granisetron $\left(1 \mathrm{mg} / \mathrm{ml}\right.$ of Kytril ${ }^{\circledR} ;$ F. Hoffman-La Roche Ltd, Basel, Switzerland) was used for the injections. Granisetron was administered into the posterior part of the upper joint compartment of the most painful TMJ during approximately $3 \mathrm{~min}$. The patients were contacted within 1 week after the granisetron injection to record any adverse effect.

Venous blood was sampled prior to the injections to measure the serum concentrations of 5-HT, rheumatoid factor, C-reactive protein, thrombocyte particle count and the erythrocyte sedimentation rate. C-reactive protein concentrations below $10 \mathrm{mg} / \mathrm{l}$ and rheumatoid factor concentrations below $20 \mathrm{IU} / \mathrm{ml}$ were considered normal.

\section{Analysis}

Serotonin was analyzed by a commercially available enzyme immunoassay kit (Immunotech, Marseille, France) with a detection limit of $0.5 \mathrm{nmol} / 1$ and a sensitivity of $0.5 \mathrm{nmol} / \mathrm{l}$. The intra-assay coefficient of variation for this assay is $<9.4 \%$ and the interassay coefficient of variation is $<9.9 \%$ according to the manufacturer. According to the manufacturer, the normal concentration to be expected for 5-HT in human serum is $300-700 \mathrm{nmol} / 1$ for males and 500$900 \mathrm{nmol} / \mathrm{l}$ for females.

\section{Statistics}

The analgesic effect was expressed by the ratio between the post-injection values of TMJ resting pain and movement pain intensities, respectively, and the corresponding pre-injection values. Friedman's repeated-measures test and Dunn's post-hoc test for compensation of multiple comparisons were used to calculate the significance of the change in pain intensity during the experimental procedure. The significance of correlations between blood variables, pre-injection pain intensities and effects of the injections were tested by the Spearman ranked correlation test. A probability level less than 0.05 was considered as significant.

\section{Results}

The serum concentration of 5-HT was above the normal range in four patients $(36 \%)$ and below it in four patients (36\%), while the thrombocyte particle concentration was within the normal range for all patients.

The serum concentration of 5-HT was negatively correlated to the change in TMJ pain intensity upon maximum mouth opening after $60 \min \left(r_{\mathrm{s}}=-.72\right.$, 

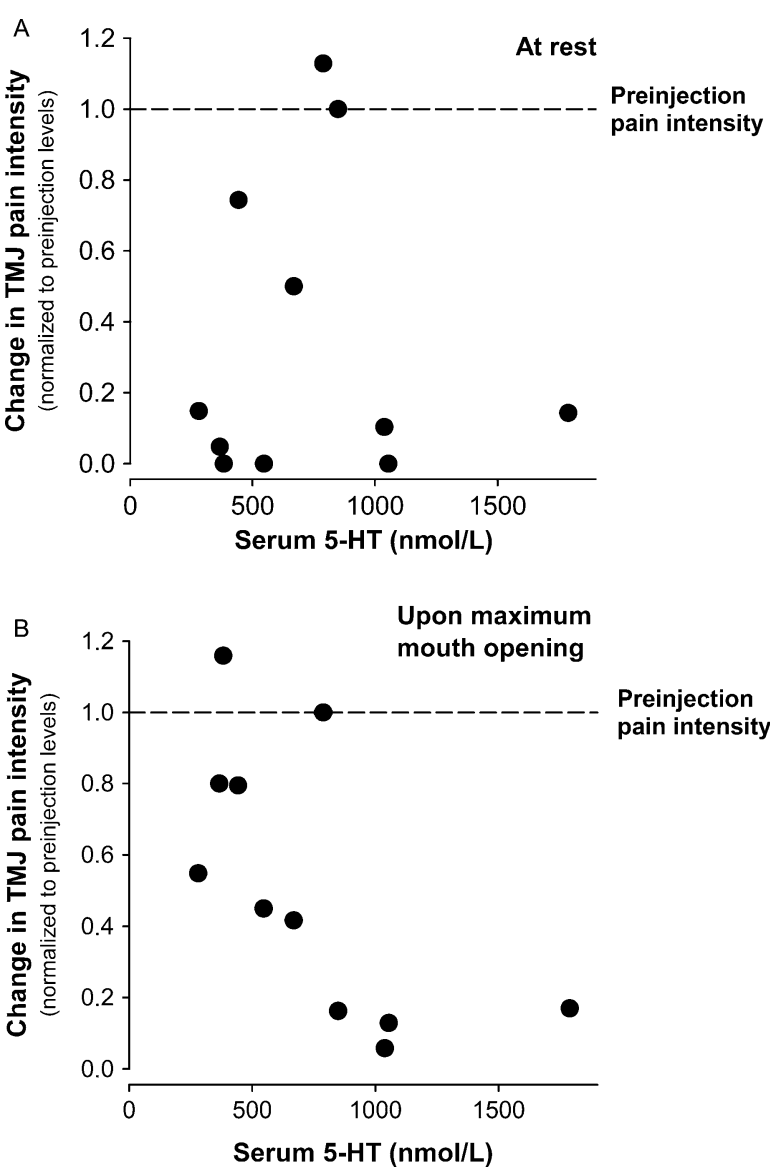

FIG. 1. Scatterplots of the relation between the serum concentration of 5- $\mathrm{HT}$ and TMJ pain intensity (A) at rest and (B) upon maximum mouth opening $60 \mathrm{~min}$ after intraarticular injection of granisetron $(3 \mathrm{mg} / 3 \mathrm{ml})$. The pain intensities are shown normalized to the pre-injection level (1.0). For TMJ pain upon maximum mouth opening there was a negative correlation to $5-\mathrm{HT} \quad\left(r_{\mathrm{s}}=-0.72, n=11\right.$, $p=0.012$ ), while no significant correlation was found for TMJ pain at rest $\left(r_{\mathrm{s}}=0.06, n=11, p=0.852\right)$.

$n=11, p=0.012$; Fig. 1); that is, the higher the serum concentration of 5-HT before injection, the larger the reduction of pain intensity. Such a relation was not found for TMJ resting pain intensity and the serum level of 5-HT ( $\left.r_{\mathrm{s}}=0.06, n=11, p=0.852\right)$.

After the granisetron injection, a significant reduction of TMJ pain intensity was present during the whole experimental period (resting pain intensity, $p=0.007$; movement pain intensity, $p=0.030$ ) on the injection side. Neither TMJ resting pain intensity nor TMJ pain intensity upon maximum mouth opening changed significantly on the non-injection side during the observation time period.

The pre-injection levels of the inflammatory markers are presented in Table 1 . The C-reactive protein level correlated positively to the erythrocyte sedimentation rate $\left(r_{\mathrm{s}}=0.75, n=11, p=0.008\right)$ and to the thrombocyte particle count $\left(r_{\mathrm{s}}=0.86, n=11, p=\right.$ 0.001 ), but did not influence the analgesic effect of granisetron.
Age was positively correlated to the ratio between TMJ pain intensity upon maximum mouth opening after $60 \mathrm{~min}$ and the corresponding pre-injection pain intensity $\left(r_{\mathrm{s}}=0.62, n=11, p=0.041\right)$; that is, a larger reduction of movement pain intensity was found in the younger patients. Age and serum concentration of 5-HT were not significantly correlated $\left(r_{\mathrm{s}}=-0.24\right.$, $n=11, p=0.498$ ).

The granisetron injections were well tolerated and there were no adverse effects following the injection during the experimental procedure or thereafter.

\section{Discussion}

This study indicates that the analgesic effect of intraarticular administration of granisetron is influenced by the level of circulating $5-\mathrm{HT}$ in patients with chronic polyarthritides.

A higher serum level of 5-HT was associated with a stronger analgesic effect of granisetron on the pain intensity upon maximum mouth opening, which is interesting from three aspects: the anti-nociceptive effect created by block of the $5-\mathrm{HT}_{3}$ receptor, the fact that the effect of granisetron seems to be specific for reduction of movement pain intensity, and the relation to serum 5-HT. It is thus very probable that the effect of granisetron after intra-articular administration can be contributed to a specific antagonism of the $5-\mathrm{HT}_{3}$ receptor. Richardson and Engel showed that 5-HT participates in the mediation of spontaneous pain from inflamed peripheral tissues by exciting or sensitizing fine afferent units by the 5- $\mathrm{HT}_{3}$ receptor. $^{6}$ Giordano and Rogers ${ }^{12}$ found that $5-\mathrm{HT}_{3}$ receptor antagonists had greater analgesic effect on chronic pain than on acute pain in a peripheral animal inflammation model, which indicates the involvement of peripheral $5-\mathrm{HT}_{3}$ receptor sites in chronic inflammatory pain and supports our findings about the $5-\mathrm{HT}_{3}$ receptor.

Activation of the $5-\mathrm{HT}_{3}$ receptor causes a longlasting sensitization even of high-threshold mechanosensitive units as well as a brief excitation of other mechanosensitive units in joints. ${ }^{13}$ Therefore, this receptor type might be active to specifically elicit TMJ movement pain; that is, pain due to mechanical stimulation of the synovial tissues upon joint movement by activation of mechanosensitive units.

Serum 5-HT, which is the main source for synovial tissue 5-HT, has previously been found to modulate inflammation and TMJ pain in patients with seropositive rheumatoid arthritis. ${ }^{14}$ Increased serum and plasma levels of 5-HT would probably cause an immediate increase of the tissue 5-HT level, resulting in increased stimulation of peripheral 5-HT receptors and, in turn, sensitization of nociceptors in the synovial tissues by, for example, the $5-\mathrm{HT}_{3}$ 
receptor. $^{4,7-9}$ Indeed, high synovial fluid levels of 5-HT in the TMJ have been associated with TMJ movement pain. ${ }^{3}$ It is therefore reason to assume that granisetron has the possibility to produce a greater analgesic effect by blocking $5-\mathrm{HT}_{3}$ receptor binding of 5-HT when there is a high 5-HT level in the serum and synovial tissues, which could explain the relation between serum 5-HT and the reduction of TMJ movement pain intensity found in the present study.

The anti-nociceptive effect of the granisetron injection found in this study could also, at least partly, be due to an unspecific effect of the injection or injection procedure per se. Examples of such unspecific effects could be dilution of endogenous pain mediators in the synovial tissues by the injected solution and placebo effects. However, since the analgesic effect was related to circulating 5-HT levels, a specific analgesic effect of granisetron is likely.

In the present study, the effect of granisetron was not related to the blood levels of inflammatory markers, which suggests that the effect of granisetron is not primarily influenced by disease activity. In addition, the blood levels of inflammatory markers as well as serotonin for the majority of patients were below the upper normal limits, which means that the patients can be considered to have a low inflammatory disease activity. Whether there is a pain-relieving effect of granisetron in more active disease is therefore so far unknown.

In conclusion, this study indicates a stronger shortterm analgesic effect on TMJ movement pain by intra-articular administration of the $5-\mathrm{HT}_{3}$ receptor antagonist granisetron in patients with high levels of circulating 5-HT.
ACKNOWLEDGEMENTS. This study was supported by grants from Karolinska Institutet, Sweden and by the Estonian Science Foundation Grant (4374), Estonia.

\section{References}

1. Voog U, Alstergren P, Leibur E, et al. Impact of temporomandibular joint pain on activities of daily living in patients with rheumatoid arthritis. Acta Odontol Scan 2003; 61: 278-282.

2. Taiwo YO, Levine JD. Serotonin is a directly-acting hyperalgesic agent in the rat. Neuroscience 1992; 48: 485-490.

3. Alstergren P, Kopp S. Pain and synovial fluid concentration of serotonin in arthritic temporomandibular joints. Pain 1997; 72: 137-143.

4. Endresen GK. Evidence for activation of platelets in the synovial fluid from patients with rheumatoid arthritis. Rheumatol Int 1989; 9: 19-24.

5. Zeller J, Weissbarth E, Baruth B, Mielke H, Deicher H. Serotonin content of platelets in inflammatory rheumatic diseases. Correlation with clinical activity. Arthritis Rheum 1983; 26: 532-540.

6. Richardson BP, Engel G. The pharmacology and function of $5-\mathrm{HT}_{3}$ receptors. Trends Neurosci 1986; 9: 424-428.

7. Martin GR, Humphrey PP. Receptors for 5-hydroxytryptamine: current perspectives on classification and nomenclature. Neuropharmacology 1994; 33: 261-273.

8. Voog O, Alstergren P, Leibur E, Kallikorm R, Kopp S. Immediate effects of the serotonin antagonist granisetron on temporomandibular joint pain in patients with systemic inflammatory disorders. Life Sci 2000; 68: 591 602 .

9. Ernberg M, Lundeberg T, Kopp S. Effect of propranolol and granisetron on experimentally induced pain and allodynia/hyperalgesia by intramuscular injection of serotonin into the human masseter muscle. Pain 2000; 84: 339-346.

10. Arnett FC, Edworthy SM, Bloch DA, et al. The American Rheumatism Association 1987 revised criteria for the classification of rheumatoid arthritis. Arthritis Rheum 1988; 31: 315-324.

11. Dougados $\mathrm{M}$, van der Linden $\mathrm{S}$, Juhlin $\mathrm{R}$, et al. The European Spondylarthropathy Study Group preliminary criteria for the classification of spondylarthropathy. Arthritis Rheum 1991; 34: 1218-1227.

12. Giordano J, Rogers LV. Peripherally administered serotonin 5-HT3 receptor antagonists reduce inflammatory pain in rats. EurJ Pharmacol 1989; 170: $83-86$

13. Birrell GJ, McQueen DS, Iggo A, Grubb BD. The effects of 5-HT on articular sensory receptors in normal and arthritic rats. Br J Pharmacol 1990; 101: 715-721

14. Kopp S, Alstergren P. Blood serotonin and joint pain in seropositive versus seronegative rheumatoid arthritis. Mediators Inflamm 2002; 11: $211-217$

\section{Received 24 June 2004}

Accepted 10 September 2004 


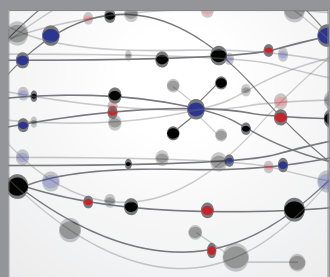

The Scientific World Journal
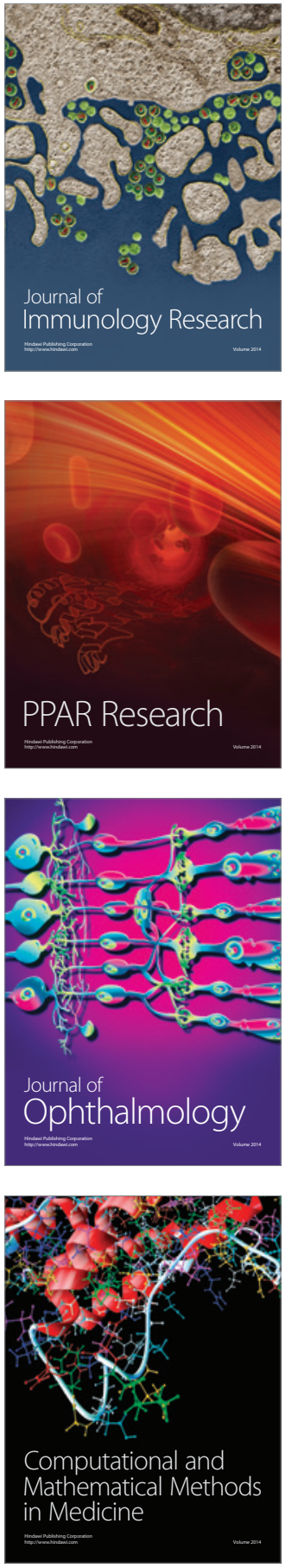

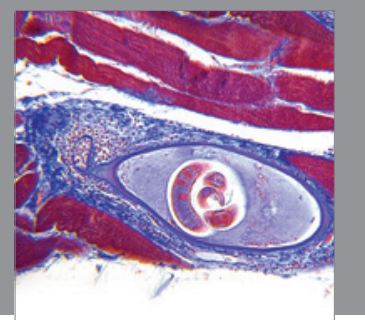

Gastroenterology

Research and Practice
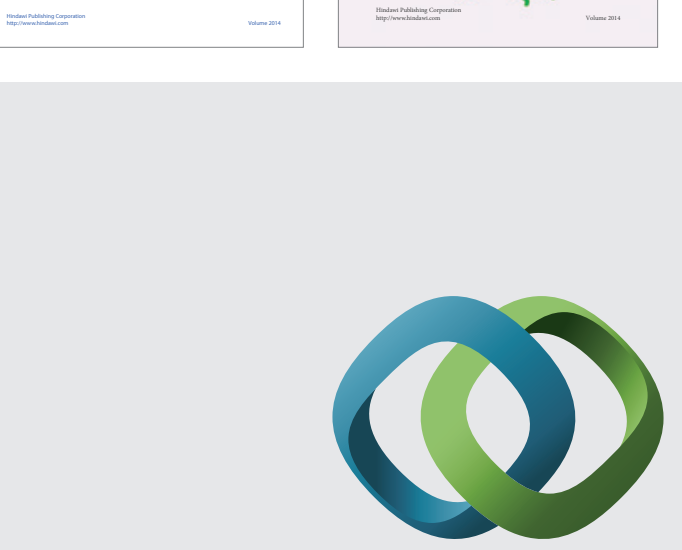

\section{Hindawi}

Submit your manuscripts at

http://www.hindawi.com
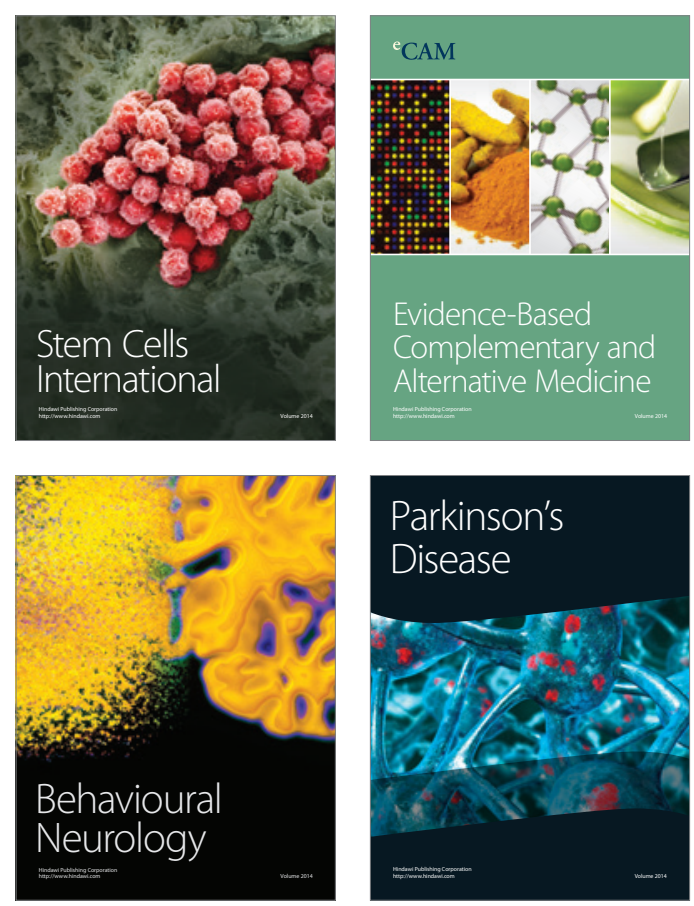

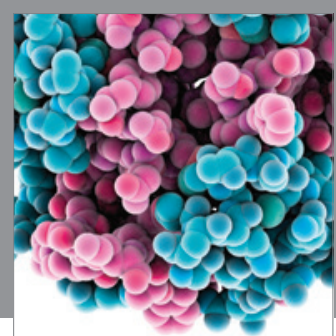

Journal of
Diabetes Research

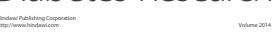

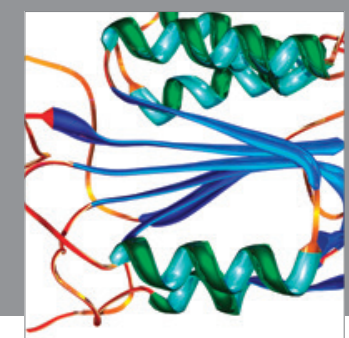

Disease Markers
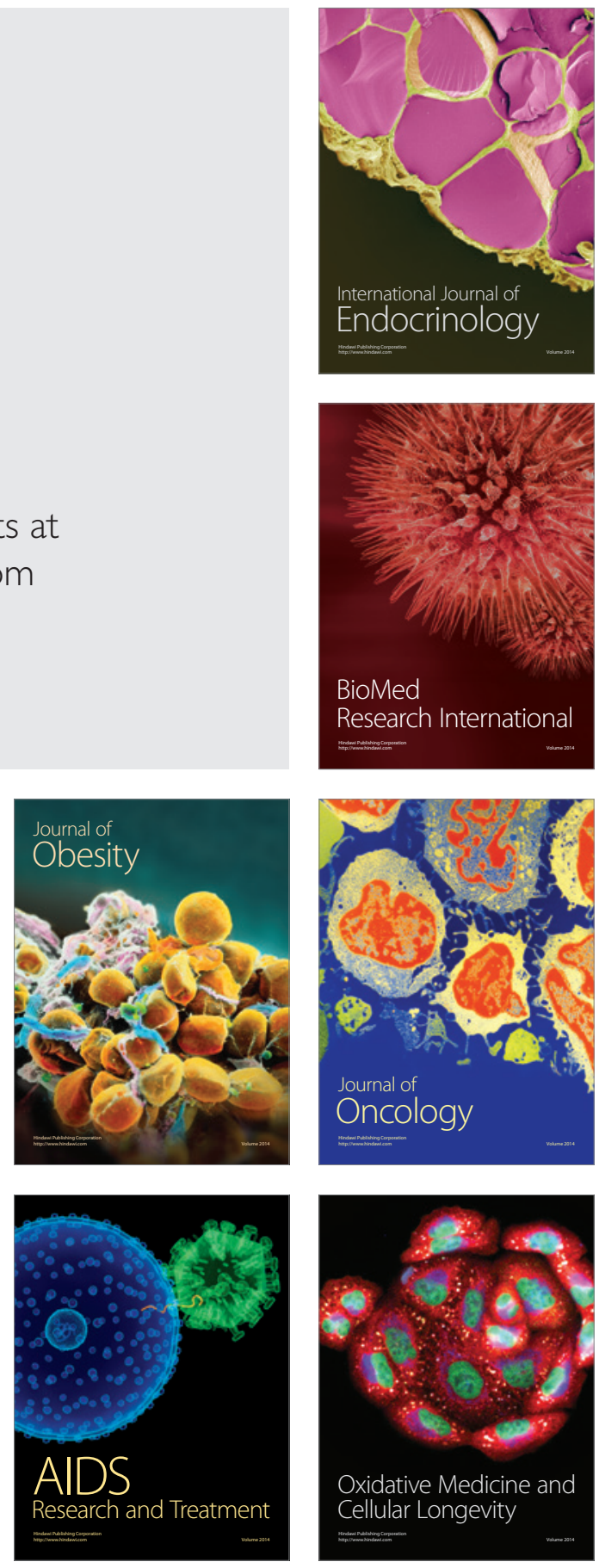